J. Lake Sci. (湖泊科学), 2005, 17(1): $35-40$

ISSN 1003 -5427; E-mail: jlakes@ niglas. ac.cn

Copyright 2005 by Journal of Lake Sciences

\title{
中国末次冰盛期以来湖泊水量变化及古气候变化机制解释*
}

\author{
薛 滨, 于 革 \\ (中国科学院南京地理与湖泊研究所,南京 210008)
}

\begin{abstract}
摘 要: 中国古湖泊数据库收录的 42 个湖泊,提供的湖泊水量每千年变化的空间信息, 可以用来系统分析中国区域末次 冰盛期以来大气环流变化的状况. 研究结果表明: 我国西部从未次冰盛期以来直至全新世中期均为较湿润的气候状况,推 测冰期内的湿润条件主要与西风带的降水以及低温低蒸发密切相关,而全新世主要为夏季风降水增加所致; 全新世晚期 气候趋干明显. 我国东部的大部分区域在冰盛期和晚冰期较为干旱; 只是在全新世有效降水状况才有大幅度的改善, 全新 世中期夏季风降水的效应仍然相当显著,控制的范围可达整个中国西部, 同时位于现代季风气候区的中国东部,有效降水 的峰值区的变化似乎存在从北往南的穿时性,南方有效降水峰值出现在晚全新世. 而西南季风区湿润状况的明显改善发 生在晚冰期, 比东南季风区发生的早, 显然这与两个季风系统的相互消长有一定的关系. 我国东北区的湿润状况改善的也 较早, 显示了独特的季风气候机制.
\end{abstract}

关键词: 中国古湖泊数据库;末次冰盛期;古水量变化;古气候机制

\section{The Lake Status Change of China since LGM and Its Significance for Palaeoclimate}

\author{
XUE Bin \& YU Ge \\ ( Nanjing Institute of Geography and Limnology, Chinese Academy of Sciences, Nanjing 210008, P. R. China)
}

\begin{abstract}
The 42 lakes compiled in the Chinese Lake Status Data Base (CLSDB), has provided the information of the spatial changes of lake status for each one-thousand year, which can be purposed for research on the atmospheric circulation changes of Chinese region since LGM. The results have shown that, the relatively wet conditions of western China from LGM to Mid-Holocene was probably related to the precipitation brought by the westlies and the low evaporation in Glacial period, and summer monsoon precipitation in Holocene. And the climate turned drier since late-Holocene. Most area in eastern China during LGM and late-Glacial was relatively dry, and turned wetter in Holocene. The summer monsoon precipitation during Mid-Holocene might reach the whole western China. In eastern China, there exists the diachronity for the maximum effective precipitation from north to south during Holocene, occurring during late-Holocene in southern china. The wet condition of southwestern China occurred clearly in late-Glacial, which is earlier than in southeastern China, suggesting that a balance occurred between these two monsoon systems. The earlier occurrenceof wet conditions in northeastern China suggests an independent monsoon systems in this area.
\end{abstract}

Keywords : Chinese Lake Status Data Base; Last Glacial Maximum; lake status; palaeoclimate

湖泊是地表水载体, 对当前水资源短缺、水环境恶化、洪涝灾害等重大环境问题反映敏感. 西部内陆湖 泊咸化、萎缩、甚至干涸; 青藏高原湖泊面积锐减; 长江中下游湖泊快速淤积、严重污染, 以及东北湖泊的沼 泽化,湖泊水量的变化已成为制约区域社会经济发展的重要因素. 因此,对区域湖泊水量变化的预测显得尤 为紧迫. 同样, 作为未来水量变化预测的参照系, 进行湖泊古水量的恢复研究, 也有极为重要的意义 ${ }^{[1]}$.

单个湖泊的水量变化是流域范围内水量平衡的综合体现,而区域同步的湖泊水量波动可以指示区域降 水和有效降水的变化,并进而可以反映水汽输送与大气环流的空间格局. 因此,综合大范围湖泊水量波动数 据, 建立相应的古湖泊数据库,进而恢复区域乃至全球的古气候状况,这已成为第四纪科学研究领域最有成 效的途径之一 ${ }^{[2]}$. 目前全球及不同区域的古湖泊数据库已逐渐形成, 中国古湖泊数据库也已初步建立 ${ }^{[3]}$,

* 国家重点基础研究发展规划项目(2002CB412300)、中国科学院长江项目 (KZCX1 - SW - 12 - 1) 和百人计划项目 联合资助. 2003-09-16 收稿;2004-12-03 收修改稿. 薛 滨, 男,1970 年生, 博士, 副研究员; E-mail: bxue@ niglas. ac. cn. 
使得我们有条件通过古湖泊数据库产生的水量记录, 进行湖泊地质资料的综合集成研究, 进而分析空间上 表 1 中国古湖泊数据库 (第一版) 收录湖泊的基本信息

Tab. 1 The basic data of the collected lakes in CLSDB ( Ver. 1) 的古水文变化特征和古大气环流状况.

末次冰盛期以来中国气候环境经

\begin{tabular}{|c|c|c|c|c|c|}
\hline 湖 泊 & $\begin{array}{c}\text { 现代面积 } \\
\left(\mathrm{km}^{2}\right)\end{array}$ & $\begin{array}{l}\text { 纬度 } \\
\left({ }^{\circ} \mathrm{N}\right)\end{array}$ & $\begin{array}{l}\text { 经度 } \\
\left({ }^{\circ} \mathrm{E}\right)\end{array}$ & $\begin{array}{l}\text { 海拔 } \\
(\mathrm{m})\end{array}$ & $\begin{array}{l}\text { 记录长度 } \\
\text { (aB. P. ) }\end{array}$ \\
\hline 艾丁湖 & 5 & 42.67 & 89.27 & -155 & 50000 \\
\hline 阿克赛钦 & 160 & 35.20 & 79.83 & 4840 & 35000 \\
\hline 阿其格库勒 & 345 & 37.07 & 88.37 & 4250 & 17000 \\
\hline 阿什库勒 & 10.5 & 35.73 & 81.57 & 4683 & 16000 \\
\hline 白碱湖 & 古湖 & 39.15 & 104.17 & 1282 & 39000 \\
\hline 白素海 & 很小 & 42.58 & 115.9 & 2000 & 13250 \\
\hline 巴里坤湖 & 112.5 & 43.70 & 92.80 & 1575 & 37000 \\
\hline 班戈湖 & 135.4 & 31.75 & 89.57 & 4520 & 20500 \\
\hline 班公错 & 412 & 33.70 & 79.42 & 4241 & 39600 \\
\hline 贝力克库勒 & 4.4 & 36.72 & 89.05 & 4680 & 13000 \\
\hline 大鬼湖 & 0.1087 & 22.85 & 120.85 & 2150 & 2600 \\
\hline 察尔汗盐湖 & 约 460 & 36.93 & 94.99 & 2675 & 38000 \\
\hline 查干诺尔 & 21 & 43.27 & 112.9 & 920 & 18000 \\
\hline 柴窝堡湖 & 约 29 & 43.50 & 87.90 & 1092 & 30000 \\
\hline 七彩湖 & 0.28 & 23.75 & 121.23 & 2890 & 4700 \\
\hline 错那 & 174 & 32.03 & 91.47 & 4590 & 35000 \\
\hline 大、小柴旦盐湖 & 约 104.9 & 37.83 & 95.23 & 3110 & 24800 \\
\hline 洱海 & 249 & 25.84 & 99.98 & 1974 & 23000 \\
\hline 额吉绰尔 & 10 & 45.23 & 116.5 & 829.2 & 15200 \\
\hline 抚仙湖 - 星云湖 & 211 & 24.5 & 102.88 & 1720 & 40000 \\
\hline 苟弄错 ～～～～ & 2.9 & 34.35 & 92.2 & 4670 & 20000 \\
\hline 红山湖 & 4.3 & 37.45 & 78.99 & 4870 & 17200 \\
\hline 呼伦湖 & 2339 & 48.90 & 117.40 & 545 & 34000 \\
\hline 吉兰泰盐湖 & 17.81 & 39.75 & 105.7 & 1023 & 17200 \\
\hline 龙泉湖 & 干涸 & 30.87 & 112.33 & 150 & 9600 \\
\hline 罗布泊 & 干涸 & 40.29 & 90.80 & $780-795$ & 20800 \\
\hline 玛纳斯湖 & 750 & 45.45 & 86 & 251 & 32000 \\
\hline 曼兴湖 & 1.5 & 22 & 100.6 & 1160 & 27400 \\
\hline 南村古湖 & 干涸 & 24.75 & 110.4 & 160 & 6400 \\
\hline 宁晋泊 & 干涸 & 37.25 & 114.75 & 26 & 18000 \\
\hline 北甜水海 & 8 & 35.70 & 79.37 & 4800 & 18000 \\
\hline 萨拉乌苏古湖 & 干涸 & 37.7 & 108.6 & 1300 & 220000 \\
\hline 杀野马湖 & 0.04 & 28.83 & 102.2 & 2400 & 7700 \\
\hline 头渚古湖 & 干涸 & 23.82 & 120.89 & 650 & 30000 \\
\hline 乌兰乌拉湖 & 544.5 & 34.8 & 90.5 & 4854 & 18500 \\
\hline 乌鲁克库勒 & 15 & 35.67 & 81.62 & 4687 & 7000 \\
\hline 小沙子湖 & 25 & 36.97 & 90.73 & 4106 & 13000 \\
\hline 金川西大甸子 & 干涸 & 42.33 & 126.37 & 614 & 10200 \\
\hline 兴凯湖 & 4800 & 45.2 & 132.2 & 69 & 64000 \\
\hline 扎布耶湖 & 243 & 31.35 & 84.07 & 4421 & 37600 \\
\hline 扎仓茶卡 & 109.75 & 32.60 & 82.38 & 4328 & 26000 \\
\hline 兹格塘错 & 184 & 32.08 & 90.83 & 4560 & 21000 \\
\hline
\end{tabular}

历了显著的变化. 不同的地质证据均表 明地处亚热带至温带的中国大陆不同 气候时期的气候对比明显 ${ }^{[4]}$. 本文拟 根据中国古湖泊数据库产出的古水量 记录, 分析并解释中国末次冰盛期以来 不同区域湖泊水量变化特征, 及其指示 的地表有效降水分布状况, 进而恢复我 国末次冰盛期以来有效降水及大气环 流的时空演化格局.

\section{1 数据来源及研究方法}

湖泊古水量数据资料来源于中国 古湖泊数据库 (CLSDB $)^{[3]}$. 该数据库 的建立主要以公开发表的文献为基础. 自上个世纪 80 年代以来地貌学与第四 纪古环境学家在我国进行了大量的湖 泊钻孔和剖面研究, 发表了数百篇中文 和英文文献, 这些文献是该数据库的资 料基础.

古湖泊数据库的建立不仅仅是一 个数据库的收集汇编工作, 更需要对所 有的资料进行大量的分析研究以重建 古湖泊水量. 湖泊水量的变化, 包括湖 泊水位、湖泊面积、湖泊深度以及湖水 咸淡等变化数据, 是建立在对逐个湖泊 地貌、湖泊钻孔、剖面沉积物性质、水生 植物花粉及其它微体生物组合与丰度 的变化、湖泊和盆地内地貌证据、考古 及历史文献记载等的系统分析上. 该数 据库尽可能综合多项上述地质证据, 对 湖泊过去水量状况作出统一的解释. 同 时, 为了与全球古湖泊数据库一致, 尽 可能系统排除那些受非气候因素 (如 洪水、火山活动、构造运动、流域侵蚀、 人类活动等) 、非直接气候因素 (如冰 川融水、海面升降、跨流域地下水等因

素可导致加快或延缓湖泊水位变化) 影响的湖泊水量记录, 因此数据库产生的每个湖泊的古水量记录能较 好地反映该湖泊流域的降水 $(P)$ 和有效降水 (降水量减蒸发量, $P-E$ ) 状况 ${ }^{[2]}$.

数据库将湖泊各种地质证据转化成相对现代水量的高程、面积、深度、盐度的湖泊水量指标. 最终根据 这些指标的综合判断划分出湖泊状况的数字化等级. 由于数据库中不同湖泊水量记录的详细程度不同, 有 的湖泊在其有记录的整个演化历史过程中仅能区分出 2 级变化 (低、高), 有的湖泊可分辨出多级变化 (如 
很低, 较低, 中等, 较高, 很高), 为了进行不同湖泊之间的比较, 清楚地辨析区域湖泊水量波动趋势, 根据不 同水量记录在整个湖泊历史中出现的频率, 分别在 0-25\%、25\%-75\%、75\%-100\% 为高、中、低三级水量 分类. 采用三级重新分类, 区分出高、中、低三级水量, 分别数字化为 $3 、 2 、 1$. 为了反映古湖泊水量相对于现 代的变化, 把每个湖泊数字化的 3 级古水量表示成与现代的级别相减, 这样可以获得 5 级相对现在的水量 变化,其 $2 、 1 、 0 、-1 、-2$ 共 5 级分别指示气候状况很湿润、湿润、无变化、干旱、很干旱 ${ }^{[3]}$.

目前中国古湖泊数据库 (第一版) 共收录并研究了 42 个湖泊的古水量资料, 表 1 给出了这 42 个湖泊点 的基本信息. 各湖泊点水量恢复参考文献来源较多,详细见本文参考文献 $[3]$.

\section{2 末次冰盛期以来不同区域古水量变化及其指示的大气环流状况}

为了能较清楚的辨析末次冰盛期以来中国古湖泊水量变化的过程, 笔者根据数据库中湖泊水量三级重 新分类的最终结果, 与现代相减得出的距平值 (5 级), 按 1000 年的间距作出空间上的湖泊水量距平演化图 （图 1), 这种湖泊水量相对现代差值反映的地表湿度状况的变化,可以用来讨论末次冰盛期以来每千年的 湖泊水量时空演化特征, 以及不同区域水量平衡的空间分布状况,进而可以深人研究与西风带及季风环流 相关的大气环流变化信息, 及相应的水汽循环的动力机制.

\section{1 末次冰盛期 (约 18 - 16 kaB. P. )}

我国东部的湖泊记录偏少, 并且基本上表现为低水量的特征 ${ }^{[3]}$; 总体相对现代 (0 kaB. P. ) 而言 (图 1), 我国西部湖泊水量总体较现代大, 湖泊水位比现代高、面积比现代大、水质比现代淡化 ${ }^{[5]}$, 这些特征与我国 中、东部湖泊的低水量或干枯湖盆形成鲜明的反差. 云南高原西北部的湖泊也为高水量, 但到南部却为低水 量; 青藏高原与新疆的高湖泊水位的状况连成一片, 只是在青藏高原的东北部, 如青海湖才为低湖面、低水 量的特征 ${ }^{[6,7]}$. 这些西部的湖泊呈现高湖面的特征, 与中亚和地中海地区的高湖面连成一带, 但南与印度中 南部的低湖面、北与中西伯利亚若干个低湖面皆形成反差 ${ }^{[5]}$. 对比国际古气候模型模拟的结果, 显然该高 水量与西风带强度和位置变化有关, 欧亚大陆西侧大陆冰流的强盛、北极区海冰的扩大以及欧亚大陆东侧 多年冻土的发育使得欧亚大陆冷源作用加强,造成冬季风强盛, 迫使西风带位置南迁, 同时东亚夏季风的萎 缩也诱使西风气流全年强盛, 西风带的强盛与南迁将提供冷空气南侵比现代更加频繁、有利于冷暖气流交 汇在比现代更南的纬度生成的环流形势, 这可能是诱发我国西部降水增多的重要生成条件 ${ }^{[5}$. 当然冰期中 的低温引起了蒸发量降低, 可能导致湖水相对损失减少, 也是湖泊水量正向平衡的一个主要原因 ${ }^{[8]}$, 使得 高水量的状况能够持续相当一段时间 ${ }^{[5]}$. 我国东部大范围的低水量或干涸湖盆为冬季风强盛水汽来源较 少的结果, 同时, 海面大幅度的退缩、及陆架的大范围出露, 水汽传输途径趋远, 也是湖泊水量较少的原因. 至于我国西南地区的高水量, 是否与西南、东南夏季风的退缩, 冬季风的位置南进, 冬、夏季风相互作用极锋 的位置在此有较长期的逗留有关 ${ }^{[9]}$, 目前还不得而知.

\section{2 晚冰期 (约 15 - 11 kaB.P.)}

我国西部湖泊仍然以中等至高水量状况为主, 而东部特别是东南部的湖泊记录仍然较少 (图 1 ). 这种 湖泊水量距平反映的地面有效湿度状况表明,我国西部继续维持相当湿润的条件,并且一直维持了整个晚 冰期, 只是在晚冰期的后期,西部的部分湖泊水量状况才和现今接近, 因此,在末次冰盛期后的晚冰期内,西 风带的位置北移和强度减弱并不显著, 冬季风仍然相当强盛, 原因主要在:一方面, 欧亚大陆陆地冰流、冻土 及北极区海冰仍然维持相当的规模, 另一方面, 北半球太阳辐射的冬夏季节旋回差异加大将放大季风环流, 中低纬地带夏季季风逐渐增强的同时, 冬季季风仍然相当强盛 ${ }^{[4]}$. 因此, 东部干旱的状况也仍然没有得到 明显改善. 但是,一个比较明显的变化是内蒙古东部及东北的湖泊记录逐渐增加,尽管有干、湿等不同状况 并存, 而总体反映的有效湿度状况呈逐渐增加趋势, 尤其在晚冰期后期约 $12 \mathrm{kaBP}$ 更加明显; 对比我国西南 地区 (云南) 的湖泊, 高水量的比例也有所增加, 反映的有效湿度状况较好, 预示随全球温度的升高, 西南季 风的爆发较早, 而且也是在 $12 \mathrm{kaB}$. P. 达到最盛, 普遍表现出湿润的状况.

\section{3 全新世早期 (约 $10-8 \mathrm{kaB}$. P. )}

全新世开始我国不同地区的湖泊水量记录更加丰富, 不仅在中国西部, 东部的大部分区域 (除东南外) 均有较多的记录. 我国西部湖泊总体仍然反映了比现代水量大的特点, 在该时期后期 ( 8 kaB. P. ), 我国西 


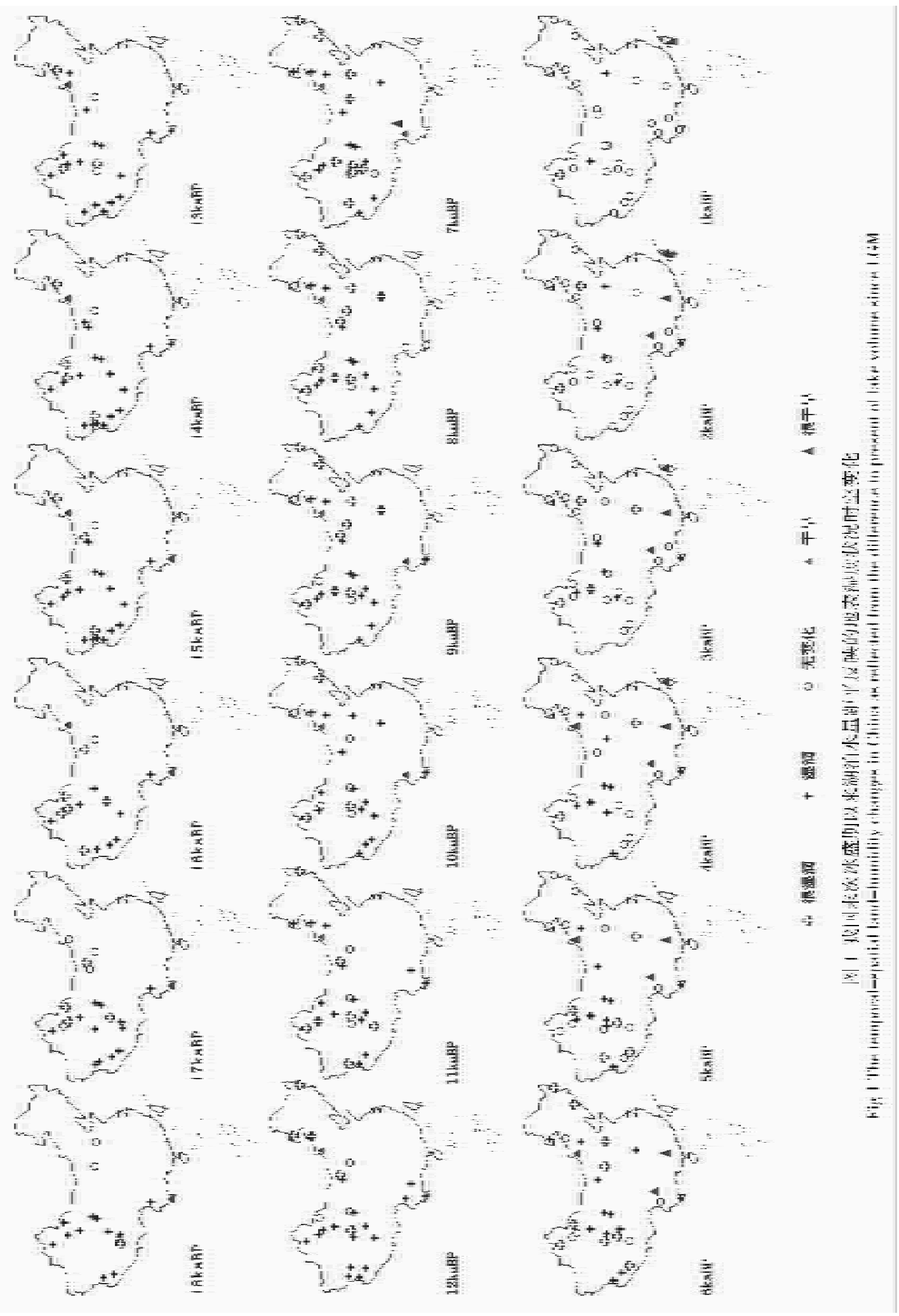


北地区湖泊的高水量比例逐渐增加. 西南地区的湖泊水量距平同前期相比, 明显减弱, 气候干旱状况明显. 东部及东北的湖泊水量距平仍然总体反映的是较现在湿润的状况,但是夹杂零星的“没变化” 和“干旱” 的 记录 (图 1), 内蒙古东部及其以北的湖泊湿润状况较前期有一定程度的减弱.

我国西部全新世初期相当湿润的气候环境,用西风气流带来水汽进行解释显然是不合适的,欧亚大陆 西部冰流以及冻土范围在该时期已显著减少,冬季风的效应明显减弱,而夏季太阳辐射较高,造成海陆温差 加大,东亚季风的扩张而使该区夏季季风雨和高原对流雨增加, 是该区湿润气候形成的最主要原因. 我国东 部现东南季风控制区,包括东北均为高水量的状况,显然,这与夏季风的加强有明显的关系,随北半球夏季 太阳辐射在全新世初达到鼎盛, 冬夏季风相互作用的极锋位置显著北推, 在现季风敏感带附近及以北的地 区有效降水状况首先得到明显的改善 ${ }^{[10]}, 9 \mathrm{kaB}$. P. 开始西北新疆地区湿润状况的普遍改善即是一个例证. 当然,在现季风盛行区的湖泊水量也有显著的增加. 云南湖泊的高水量已有所减少, 反映西南季风在进人全 新世后一定程度的萎缩, 显然, 与北半球夏季太阳辐射吻合较好 ${ }^{[4]}$.

\section{4 全新世中期 (约 7 -5 kaB. P. )}

图 1 显示, 我国华南开始有湖泊记录,但反映为较干旱的气候的特征; 长江中下游的湖泊水量距平状况 略有下降, 内蒙古的湖泊水量距平基本同前期,略呈减少趋势; 东北仍然以湿润特征为主; 西南地区趋向干 旱; 我国西部青藏高原及新疆在这一时期湖泊水量距平反映的仍是总体湿润的状况,但是在该时段后期,出 现较多和现代干旱湖泊环境接近的气候条件.

$6 \mathrm{kaBP}$ 前后为距现今最近的一个温暖时期,并且一直是气候模型模拟的关键时段之一 ${ }^{[11]}$. 我国的大部 分地区也均为比较湿润的气候状况, 只是在西南与华南区域略偏干旱. 从大气环流状况分析, 东亚夏季风随 夏季太阳辐射变化而明显减弱, 同时, 北半球冰盖消融殆尽, 冬季风极度萎缩, 西风带北移也趋萎缩, 但是从 有效降水范围分析, 夏季风影响的范围相当大, 秦伯强等认为夏季风的影响甚至可以覆盖到中亚的大部分 地区 ${ }^{[12]}$. 对此较多的解释是: 陆地植被覆盖条件的大幅度改善是夏季风效应显著的主要原因,植被的反馈 作用使得陆地反射降低,蒸发作用减弱,地表有效湿度增加. 而华南与西南干旱的状况可能与副热带高压位 置的北移与西伸有关, 副热带高压南侧以从大陆向海洋的离岸风占主导, 引起夏季的少雨和干旱频率增加, 可能是中全新世该地区湖泊水量偏低、地面湿度减小的主要原因 ${ }^{[9]}$, 至于这种推论是否准确,还需该区更 多的古湖泊水量证据及其它地质证据的证实.

\section{5 全新世晚期 (约 $4 \mathrm{kaB} . P$. - 现代)}

全新世中期以后, 特别是 $3 \mathrm{kaB} . \mathrm{P}$. 后, 湖泊水量资料显示了气候类型逐渐向现代过渡,图 1 中“无变化” 的记录逐渐增加. 我国华南的湖泊记录继续增加, 湖泊记录的出现可以说明水汽来源一定程度的增加, 但是 在大范围上总体反映仍以干旱状况为主, 只是到近千年出现 “没变化” 的记录; 长江中下游的湖泊在从 5 $\mathrm{kaB}$. P. 到 $3 \mathrm{kaB}$. P. 前出现高水量的记录, 反映为非常湿润的状况, 其后气候逐渐过渡为与现代相似的情况; 内蒙古和东北的湿度情况较前期均有明显的下降,基本和现代的情况一致; 云南高原的湖泊水量距平情况 基本与全新世中期一样; 我国西部从 $3 \mathrm{kaB}$. P. 湖泊水量基本接近现代,为低水量和干旱的特征, 反映进人新 冰期在我国西部干旱化趋势明显,只有极少数湖泊仍然维持高水量或中等水量的特点.

比较特殊的是, 长江中下游的湖泊反映在 $3 \mathrm{kaB}$. P. 及以前, 该区环境较为湿润 (图 1), 是一个较为明显 的成湖期,而到近千年 (图 1) 华南的湖泊反映的湿度状况似乎有增加趋势, 看来随夏季太阳辐射的降低, 我 国东部季风区的有效降水的峰值区, 似乎存在一个往南逐渐退缩的穿时性 ${ }^{[10]}$.

图 1 反映的是 $18 \mathrm{kaB}$. P. 以来的不同时期湖泊水量距平变化状况,这也从另一方面说明,我国大多数湖 泊现代的水量状况, 在其最近的冰期 - 间冰期旋回历史内基本以低水量为主, 只是在华南及台湾的湖泊, 似 乎现代普遍为中高水量, 构成全国范围内显著的区域特点, 显然与该区现今湿润的气候密切相关.

\section{3 讨论和结语}

中国古湖泊数据库提供了系统、规范的空间水量变化资料, 有助于我们研究中国大陆尺度上的有效降 水变化过程, 及相应的大气环流状况. 同时, 该数据库提供的空间尺度上的地面有效湿度变化信息, 也可以 用来作为一个评价各种古气候模拟的参照标准. 
我国西部从末次冰盛期以来直至全新世中期均为较湿润的气候状况, 冰期内的湿润条件主要与西风带 的降水密切相关, 同时低温低蒸发也是一个重要的因素; 而全新世主要为夏季风降水增加所致;全新世晚期 气候环境趋干明显. 我国东部的大部分区域在冰盛期和晚冰期较为干旱; 只是从全新世初期开始有效降水 状况才有大幅度的改善, 即使在太阳辐射略趋萎缩的全新世中期, 由于地面植被覆盖的反馈作用, 夏季风降 水的效应仍然相当显著,控制的范围可达整个中国西部, 同时在现代季风气候区的中国东部,有效降水的峰 值区的变化似乎存在从北往南的穿时性. 西南季风区湿润状况的明显改善发生在晚冰期, 比太平洋季风区 发生的早, 显然这与两个季风系统的相互消长有一定的关系. 我国东北区的湿润状况改善的也较早, 显示了 独特的季风气候机制.

这项研究国内目前刚刚起步, 主要是作为中国区域的古湖泊数据库还刚形成. 上个世纪 80 年代后期完 成的牛津湖泊数据库 ${ }^{[13]}$, 作为全球性的古湖泊数据库, 收集了主要源于 20 世纪 80 年代文献的中国 9 个湖 泊点资料;90 年代初方金琪 ${ }^{[1]}$ 曾收集了大量中国古湖泊资料,并绘出了距今 3 万年以来不同特征时期湖 泊水位分布图,然而,其中的 $1 / 3$ 湖泊没有进行高低水位的判识,也缺乏如何恢复湖泊水位变化的分析依 据, 同时, 由于缺乏年代数据, 难以进行湖泊水位变化事件定年的可靠性评价等, 因此,这项工作由于最终没 有形成标准的国际性古湖泊数据库而停顿.

本文根据中国古湖泊数据库 (第一版) 的古水量资料, 暂对不同区域湖泊水量每千年的演化过程及分 异特点作一初步的比较, 当然期待更多湖泊古水量资料, 尤其是我国东部,特别是华东、华南地区的更多资 料的更新和输人,这样才有可能对不同区域湖泊水量演化的分异过程及其机理形成更为准确的判识.

致谢: 德国马普生物地球化学研究所 Sandy Harrison 教授在中国古湖泊数据库的建立过程中给予具体的指 导, 本所施雅风院士、王苏民研究员、秦伯强研究员、李世杰研究员在本项研究中提出了许多建设性的意见, 国内很多湖泊第四纪学家为该古湖泊数据库的建立提供了较多的有价值的资料. 在此特表谢意.

\section{4 参考文献}

[1] 于 革, 秦伯强. 预测未来气候的钥匙之一一一古气候模型与湖泊数据库的对比研究. 自然杂志, 1997, (5):293 -299 .

[2] Harrison S P, Digerfeldt G. European lakes as palaeohydrological and palaeoclimatic indicators. Quaternary Science Reviews, $1993, \mathbf{1 2}: 233-248$.

[3] Yu G, Harrison S P, XUE B. Lake Status records from China: data base documentation. Academic Report in Max-PlanckInstitute, 2001. No. 4. Jena, Germany.

[4] 安芷生,吴锡浩,汪品先等. 未次间冰期以来中国古季风气候与环境变迁. 见: 刘东生,安芷生主编. 黄土第四纪地质 全球变化(第三集). 北京:科学出版社, $1992: 14-30$.

[5] 于 革,薛 滨,王苏民等. 末次冰盛期中国湖泊记录及其气候意义. 科学通报, 2000,45(3):250-255.

[6] 陈克造, Bowler J M, Kelts K. 四万年来青藏高原的气候变迁. 第四纪研究, 1990, (1) : 21 - 30.

[7] Kelts K, Chen KZ, Lister G, et al. Geological fingerprints of climate history : a cooperative study of Qinghai Lake, China. Eclogae geol Helv, 1989, 82 (1) : $167-182$.

[8] Shi Y F, Yu G, Li B Y. Reconstruction of the $30-40$ ka BP enhanced Indian monsoon climate based on geological records from the Tibetan Plateau. Palaeogeography, Palaeoclimatology, Palaeoecology, 2001,169: $69-83$.

[9] Xue B, Yu G. The Change in atmospheric circulation since Last Interstadial as indicated by the lake-status record in China. Acta Geologia Sinica, 2000, 74(4):836-845.

[10］吴锡浩,安芷生,王苏民等. 中国全新世气候适宜期东亚夏季风时空变迁. 第四纪研究, 1994, (1) :24 - 37 .

[11] 于 革. 全球晚第四纪湖泊数据库研究. 湖泊科学, 1997,9(3):193-202.

[12]秦伯强,施雅风,于 革. 亚洲大陆湖泊在 $18 \mathrm{kaBP}$ 及 $6 \mathrm{kaBP}$ 的水位变化及其指示意义. 科学通报, 1997,42(24):2586 $-2596$.

[13] Street-Perrott F A, Marchand D S, Roberts N, et al. Global lake-level variations from 18,000 to 0 years ago: a palaeoclimatic analysis. Washington:U.S. DOE/ER/60304 - H1 TR046. U.S. Department of Energy, Technical Report, 1989: 230.

[14] Fang J Q. Lake evolution during the past 30,000 years in China and its implication for environmental changes. Quaternary Research, 1991, 36:37-60. 